\section{Photocatalysis by Au Nanoparticles: Reforming of Methanol}

\author{
Michael Bowker, Lucy Millard, Jane \\ Greaves, David James* and Jorge Soares, \\ School of Chemistry, Cardiff University, Cardiff CF10 \\ 3TB, UK and Department of Chemistry, University of \\ Reading, UK. \\ * now at Johnson Matthey Technology Centre, \\ Sonning Common, Oxfordshire.
}

\section{E-mail: bowkerm@cardiff.ac.uk}

\begin{abstract}
$\mathrm{Au} / \mathrm{TiO}_{2}$ catalysts were prepared by incipient wetness impregnation and tested for the room temperature photocatalytic reforming of methanol in aqueous solution to produce hydrogen. These catalysts proved to be active for this reaction, with the dependence on loading of gold showing a double maximum in yield at 0.2 and 2 weight \% with a low rate below $0.01 \%$ and above $10 \%$. A model is proposed for the reaction, involving band gap excitation of titania electrons to produce $\mathrm{O}^{-}$species which are then used to oxidise the methanol via adsorbed methoxy, which is formed by dehydrogenation on the metal component. The reaction is truly bi-functional and only takes place at the interface between the metal and the support.
\end{abstract}

An ideal for the future well-being of the human population of the world (and for the biota as a whole) is to find an energy source which has the following properties:

1 It must be environmentally benign, producing minimal pollution of any kind, and taking up as little useful space as possible;

2 It must have usable energy density;

3 It should be usable on a local basis - strategically eliminating dependence upon external influences;

4 It should be economically viable, which is not as simple a point as might at first be imagined, since it involves future costs of materials and government subsidies which are currently in place for various energy sources (nuclear, for instance) and which will, in turn, relate closely to item 3;
5 It needs to be technologically feasible and available.

In many ways hydrogen best fits most of these points, except for 4. It fits 1, provided that it is part of a cycle, that is hydrogen is produced from water and is burned back to water to produce energy from the exothermic oxidation of hydrogen. 2 also applies, but only if the hydrogen is used at the source of production, or is transported in a densified form (for instance, as a liquid, a high pressure gas, or condensed into a microporous high surface area solid). The technology is currently available to achieve 3 and 5, though the technology certainly can be improved. 4 is the main problem, but as stated above, hydrogen may well become economically viable in the event of a big increase in the price of oil or big taxes on fossil fuels more generally, related to the pollution they cause and their strong connection to global warming. More importantly for the West, that part of the world is currently unrealistically dependent on oil supplies from unstable parts of the world. Any responsible Western state should be investing VERY heavily, right now, in alternative energy sources, one of these being renewable and minimally-polluting hydrogen production.

The objective of this paper, then, is to describe one method of producing hydrogen, that is, by using photocatalysis, which has the potential to be used to split water using sunlight. However, the rates of this reaction are quite low and so the work described here focuses on the room temperature reforming of methanol, which does effectively split water. Previous work in this group [1-6] has involved the study of the photocatalytic production of hydrogen from various reactant mixtures, including water alone [2] but especially those containing methanol, water, and a photocatalyst (usually $\mathrm{Pd} / \mathrm{TiO}_{2}$ ) under anaerobic conditions. We and others [1-10] have shown that methanol reforming can occur on such catalysts at ambient temperature using light.The overall reaction can be written as follows, namely as the water reforming of methanol -

$$
\mathrm{CH}_{3} \mathrm{OH}+\mathrm{H}_{2} \mathrm{O} \rightarrow 3 \mathrm{H}_{2}+\mathrm{CO}_{2}
$$

The light has to have energy greater than the band gap of the titania support in order to store energy to drive the reaction, that is greater than around $3.2 \mathrm{eV}$, corresponding to a wavelength of around $350 \mathrm{~nm}$.

Gold has recently received a great deal of attention [11-13] due to its unexpected catalytic qualities. This is usually attributed to the small size of the particles in most catalysts and its manner of interaction with the support. Preparation techniques seem to be very important for determining the parameters and thus catalytic efficiency. However, Au has only rarely been used previously for photocatalysis, though Bamwenda et al reported that $\mathrm{Au} / \mathrm{TiO}_{2}$ can photocatalyse the decomposition of ethanol [14] and ethylene glycol [15]; 
we are not aware of any reports for the photocatalytic reforming of methanol. It must be noted that $\mathrm{Au} / \mathrm{TiO}_{2}$ is also active in the photoxidative degradation of VOCs [16], although $\mathrm{TiO}_{2}$ alone is also effective for such reactions. In the current paper we report that $\mathrm{Au} / \mathrm{TiO}_{2}$ catalysts have surprisingly high activity, compared with other supported metals, for methanol reforming with water. We are also interested in the comparison of this reactivity with other metals, and in any differences in the mechanism of the reaction between them.

The equipment used in this work was reported by us previously $[1,2]$. It consists of a Pyrex reaction flask, with a purge line and a septum for gas sampling. The Pyrex vessel effectively cuts off all wavelengths of less than $300 \mathrm{~nm}$. The reaction mixture (typically $0.2 \mathrm{~g}$ catalyst, $110 \mu \mathrm{l}$ methanol and $100 \mathrm{ml}$ deionised water (<10 $\mu \mathrm{mhos}))$ was placed in the flask and purged with Argon for 1 hour in order to remove dissolved gases. The mixture was stirred with a magnetic stirrer and light from the $400 \mathrm{~W}$ Xe arc lamp (Oriel model 66084) entered the vessel from the side. Samples of $0.2 \mathrm{ml}$ were taken periodically from the gas phase both prior to and after switching on the lamp. The samples were analysed for hydrogen content using a Varian 3300 gas chromatograph, with a thermal conductivity detector and an MS 13X column, $2 \mathrm{~m}$ long.

Catalyst preparation was carried out using the incipient wetness method. A number of different weight loadings of gold on titania were prepared. Typically, the preparation procedure was as follows. A stock solution of chloroauric acid, $\mathrm{HAuCl}_{4.3} \mathrm{H}_{2} \mathrm{O}$, was used and an appropriate volume of this solution was added to Degussa P25 titania to give the weight loadings reported below. The impregnated support was then dried in an oven at $110^{\circ} \mathrm{C}$ for 2 hours, after which it was ground in a pestle and mortar and calcined at $500^{\circ} \mathrm{C}$ for 2 hours. It was sieved to an aggregate size of less than $53 \mu \mathrm{m}$ before use.

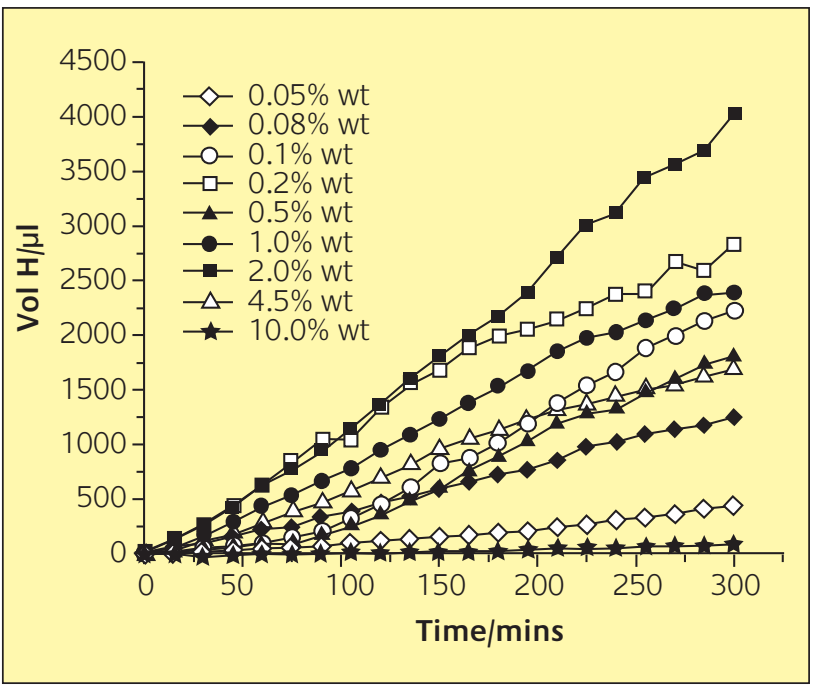

Figure 1

Hydrogen production from various weight loadings of gold on titania
In fig 1, we present the results for a variety of different loadings of Au on titania. It is clear that gold is an active catalyst for this reaction and it is interesting to note that, although producing a little less hydrogen than Pd at the maximum rate, at $2 \%$ weight loading, on a molar basis gold appears to be even better than Pd (7.9 × $10^{5}$ vs $2.7 \times 10^{5} \mu \mathrm{l}$ $\left.(\text { mol metal) })^{-1} \min ^{-1}\right)$, which is itself one of few good metaltitania catalysts for this reaction $[3,5,6]$. Fig 2 shows the effect of varying the Au loading and the effect on activity is very marked. The rate is low at low and high loadings of $\mathrm{Au}$, while loadings between $\sim 0.05$ and 5 wt. \% Au show the highest rates, with a double maximum at around 0.1 and 2 wt. \%. This is broadly similar to the behaviour for Pd [1,5], but only a single maximum was seen in that case. That maximum was proposed to be due to the nature of the active site for the reaction, which takes place at the interface between the metal nanoparticles and the support where all the reactants (adsorbed methanol, light-excited electrons and adsorbed water) can be brought together [1,5]. Thus this is an example of catalysis at a boundary between metallic and oxidic phases. This is probably the reason why, also in the case of $\mathrm{Au}$, the reaction is very low at high loadings of $\mathrm{Au}$ - there is very little perimeter area at the interface between $\mathrm{Au}$ and $\mathrm{TiO}_{2}$, and this is a kind of 'shadowing' of the photoactive support by the Au, described in greater detail previously [5].

The dual peak for gold catalysts was found to be reproducible, and therefore not a result of inaccurate catalyst preparation. The only parallel we can find with this behaviour is the early work of Sermon et al [17] for quite a different reaction, namely the hydrogenation of pent-1-ene on $\mathrm{Au} / \mathrm{SiO}_{2}$. They carried out a careful study of loading effects on this reaction and found a minimum in rate at a similar loading to our results above, though no reason for this minimum was deduced. Some studies suggest that gold can take on two distinct morphologies when

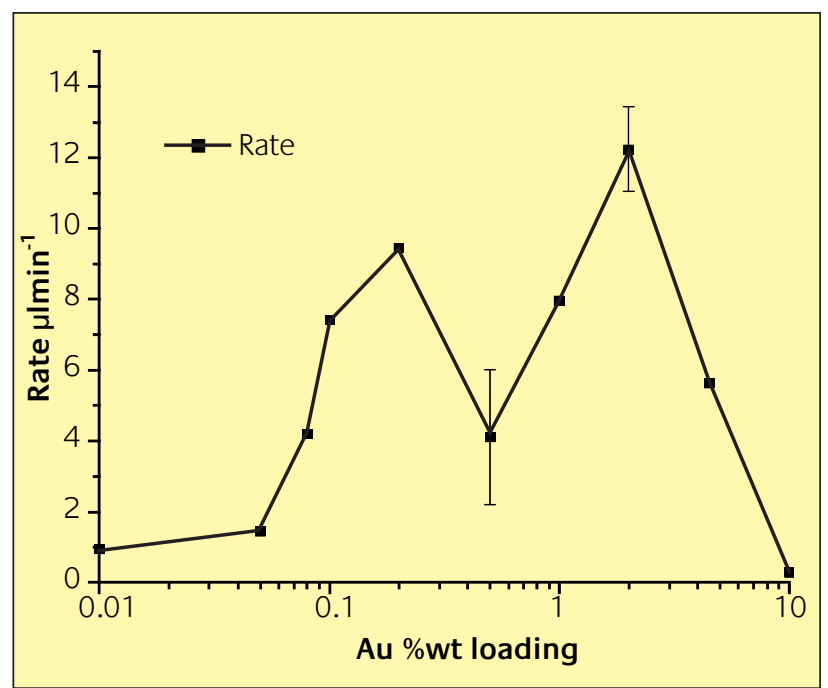

Figure 2

Rate of hydrogen production versus gold weight loading 
deposited on a planar $\mathrm{TiO}_{2}$ surface [18], and it may be that the two peaks represent the maxima for these two.

A mechanism for this reaction on $\mathrm{Pd} / \mathrm{TiO}_{2}$ was proposed earlier [1-5]. It is likely that the same basic mechanism works for this reaction too. However, there is a significant difference in the process. It was previously proposed that adsorbed $\mathrm{CO}$ is the major surface intermediate in the reaction for the $\mathrm{Pd} / \mathrm{TiO}_{2}$ catalysts and this was formed by dehydrogenation of methanol. In the absence of light the reaction did not proceed because of the strong binding of $\mathrm{CO}$ on the Pd surface, resulting in selfpoisoning of adsorption sites for methanol on the metal. Thus, if $\mathrm{CO}$ were used instead of methanol, it should have been capable of sustaining steady state catalysis, that is, hydrogen production by the photocatalytic water-gas shift reaction (CO + $\mathrm{H}_{2} \mathrm{O} \rightarrow \mathrm{CO}_{2}+\mathrm{H}_{2}$ ). In fact, this was indeed found to be the case for Pd; although the CO turnover is lower than for methanol, the reaction proceeds well at steady-state [4]. However, it does not work for $\mathrm{Au}$, presumably due to the much lower binding of $\mathrm{CO}$ on the Au surface. Thus the details of the reaction for Au are somewhat different, and so the proposed mechanism for the methanol reforming reaction is shown in fig. 3 .

In fig.3 (a), methanol adsorbs dissociatively onto the Au to form the methoxy, which, in the absence of light, terminates the reaction. The stability of methoxy on $\mathrm{Au}$ is in analogy with its stability on other group II metals, Cu [19], Ag [20] for which elements decomposition in TPD occurs above 300K. Thus it is likely that methoxy decomposes only slowly on gold at 300K and that its decomposition is speeded up in the presence of light in the following manner. The titania absorbs light to provide $\mathrm{e}^{-} / \mathrm{h}^{+}$pairs (b), and this generates an oxidising species, proposed to be $\mathrm{O}^{-}$, which is effectively the hole, $\mathrm{h}^{+}$. There is no reaction of methanol in the absence of light, implying that a photogenerated species is the oxidant. The oxidant cannot come from the normal lattice species (surface lattice $\mathrm{O}^{2-}$ ) because it would simply react in the absence of light. The proposed oxidant $\mathrm{O}^{-}$reacts at the interface between gold and titania, where the methoxy is oxidised (c), and so the particle interface is thought to be the location of the active sites, as described in detail in one of our earlier publications [5]. The vacancy left on the titania by this anion loss is then filled by water (d), which liberates hydrogen (e) and, as a result, water is the net oxidant. The vacancy (a free adsorption site, S) on gold is filled by another molecule of methanol. In this way a catalytic cycle is formed, and it can repeat itself as long as methanol and water are available. For every mole of methanol reacted, three moles of hydrogen are generated as shown in the stoichiometric equation above. The individual steps shown in fig. 3 can be summarized as follows.

a) $\mathrm{CH}_{3} \mathrm{OH}+\mathrm{S} \rightarrow \mathrm{CH}_{3} \mathrm{O}_{a}+1 / 2 \mathrm{H}_{2}$

b) $\mathrm{Ti}^{4+} \mathrm{O}^{2-}+\mathrm{h}_{-} \rightarrow \mathrm{Ti}^{3+}+\mathrm{O}^{-}$

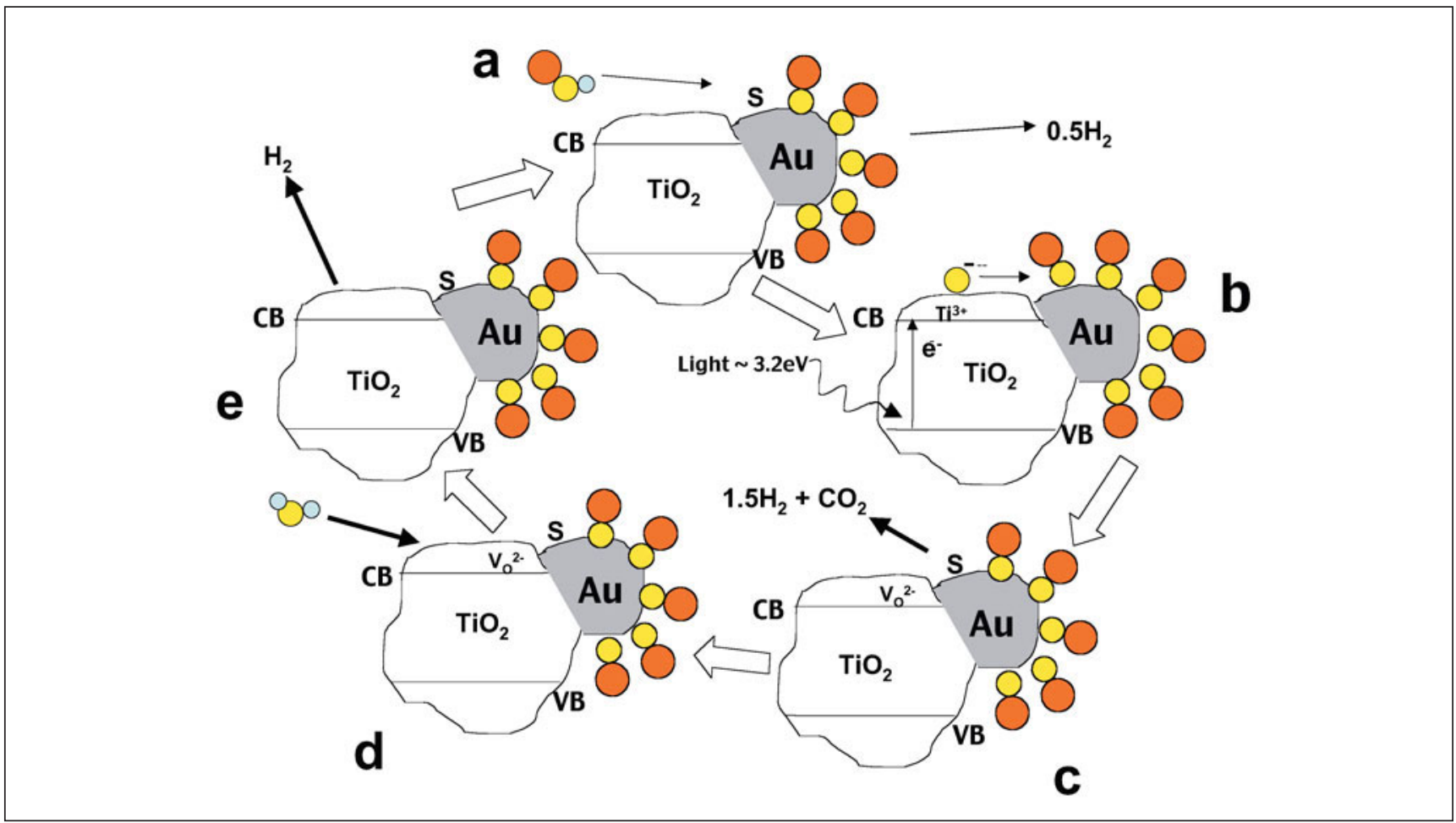

\section{Figure 3}

Schematic mechanism for the photocatalytic reforming of methanol on Au/TiO ${ }_{2}$. Red circles represent the methyl group, yellow-oxygen, blue- hydrogen. CB and VB refer to the conduction band and valence band of the solid, which are shown in a schematic way. $S$ refers to a vacant site on the metal. The photo-excited electron-hole pair formed in b is very short-lived. 
c) $\mathrm{CH}_{3} \mathrm{O}_{\mathrm{a}}+\mathrm{O}^{-}+\mathrm{Ti}^{3+} \rightarrow \mathrm{CO}_{2}+1.5 \mathrm{H}_{2}+\mathrm{S}+\mathrm{V}^{2-}+\mathrm{Ti}^{4+}$

d) and e) $\mathrm{H}_{2} \mathrm{O}+\mathrm{V}^{2-} \rightarrow \mathrm{O}^{2-}+\mathrm{H}_{2}$

No evidence for other products was found in the solution. Note that, in contrast to Pd, it is likely that the CO, if formed, is very short-lived due to its low binding to the Au surface [21] and so the surface here is probably dominated by methoxy. Further, Haruta has shown that $\mathrm{CO}$ oxidation is facile on $\mathrm{Au} / \mathrm{TiO}_{2}$ [11]. Formaldehyde is a possible product of such reaction on group 12 metals, so we checked for its presence with NMR, but it was absent from the solution. Further, experiments with formaldehyde itself show that it is unstable in the presence of light. It produces hydrogen photo-catalytically at a similar rate to methanol. In other experiments to check the effect of catalyst preparation, we found that catalysts made by deposition-precipitation were somewhat more efficient for this reaction, but only by a factor of 1.5 or so.

In conclusion, Au supported on titania is shown to represent one the best metal-support combinations for the production of hydrogen by alcohol photo-reforming under anaerobic conditions. However, that rate is still low because only photons of energy greater than the band gap of titania are utilized (that is those shorter than $~ 360 \mathrm{~nm}$.). To make this a viable technology we need to find a another type of support which is photostable in aqueous media, which has not yet been found. Grätzel [22] has created a system which appears to be able to split water with visible light, but is a very complex system, using a variety of chemical intermediates. We must remember that the thermodynamic free energy requirement to split liquid water is in the blue/violet, $\left(\Delta \mathrm{C}^{\circ}=237 \mathrm{~kJ} \mathrm{~mol}^{-1}\right.$, $\sim 500 \mathrm{~nm}$.) and so it is likely that gas phase water splitting $\left(\Delta \mathrm{G}^{\circ}=229 \mathrm{~kJ} \mathrm{~mol}^{-1}\right.$, _ $\sim 520 \mathrm{~nm}$.) will give the first real success for efficient water splitting since the integrated photon availability from sunlight in that range is higher. Note that we are currently carrying out work on the reaction above in the gas phase and have had success with that both with $\mathrm{Pd}$ - and $\mathrm{Au}-\mathrm{TiO}_{2}$ catalysts.

\section{Acknowledgements}

We are happy to acknowledge support from the EPSRC for students LM, JG and to Johnson Matthey for additional support to JG and to the Portuguese Government for support for JS.

\section{About the Authors}

Professor Michael Bowker is involved in various aspects of nanoscience, surface science and catalysis. He is Professor of Surface Chemistry at Cardiff University, having previously been Professor of Physical Chemistry at Reading University.
Prior to that he was a founder of the Leverhulme Centre and the Surface Science Centre at Liverpool University. He spent 8 years in industry, with $\mathrm{ICl}$ at their Corporate Laboratory after spending two years in the Chemical Engineering Department at Stanford University. He has 200 publications and the research group currently consists of 12 people 4 of whom are working on various aspects of Au catalysis and nanoscience. Lucy Millard is completing her PhD thesis on aspects of photocatalyitic hydrogen production at Reading University.

Jane Greaves is completing exprimental work on aspects of photocatalytic hydrogen production using gold catalysts at Reading University.

Jorge Soares is completing his PhD work at Cardiff University on novel Au catalysts for oxidation reactions.

\section{References}

1 A. Dickinson, D. James, N. Perkins, T. Cassidy and M. Bowker, J. Mol. Catal. A, 146(1999) 211

2 A. Dickinson, 'Photocatalytic Hydrogen Production', PhD Thesis, University of Reading, 1997

3 D. James, MSc Thesis, University of Reading, 1999

4 L. Millard and M. Bowker, J. Photochem and Photobiol. A, 148(2002)91.

5 M. Bowker, D. James, P. Stone, R. Bennett, N. Perkins, L. Millard, J. Greaves and A. Dickinson, J. Catal., 217(2003)427

6 M. Bowker, L. Millard, J. Greaves, D. James and J. Soares, in Proceedings of the Gold 2003 conference at http://gold.dev.cfp.co.uk/discover/ sci_indu/gold2003/index.html paper S36a1473p1148

7 T. Kawai and T. Sakata, J. Chem. Soc. Chem. Comm. (1980) 694

8 T. Sakata and T. Kawai, Chem. Phys. Letts. 80 (1981) 341

9 S. Naito, J. Chem. Soc. Chem. Comm., (1985) 1211

10 P. Pichat, J-M Herrman, J. Disdier, H. Courbon, M-N Mozzagena, Nouv. J. Chem., 5 (1981) 627

11 M. Haruta, S. Tsubota, T. Kobayashi, H. Kageyama, M. Genet and B. Delmon, J. Catal., 144 (1993) 175

12 G.C. Bond and D.T. Thompson, Cat. Rev. - Sci. Eng., 41 (1999) 319

13 G.C. Bond and D.T. Thompson, Gold Bulletin, 33 (2000) 41

14 G. Bamwenda, S. Tsubota, T. Nakamura, M. Haruta, J. Photochem. Photobiol., 89 (1995) 177

15 G. Bamwenda, S. Tsubota, T. Kobayashi, M. Haruta, J. Photochem. Photobiol., 77 (1994) 59

16 A. Orlov, D. Jefferson, N. Macleod and R.M. Lambert, Cat. Letts., 92 (2004) 41

17 P. Sermon, G.C. Bond and P.B. Wells, J. Chem. Soc. Farad. Trans I, 74 (1978) 385

18 L. Zhang, R. Persaud and T.E. Madey, Phys. Rev. B, 56 (1997) 10549

19 M. Bowker and R.J. Madix, Surf. Sci., 95 (1980) 190

20 I. Wachs and R.J. Madix, Surf. Sci. 76 (1978) 531

21 D. Outka and R.J. Madix, Surf. Sci., 179 (1987) 351

22 For a review, see M. Grätzel, CATTECH, 5 (1999) 4 